\title{
Capacity Building in a Tanzania Nursing School: An International Collaboration Case
}

\author{
Jim Katzenstein \\ California State University Dominguez Hills \\ William David Brice \\ California State University Dominguez Hills
}

This case study describes a collaborative project between a private nursing school in Africa, and the faculty of a public university in California. The project embeds the nursing school within the framework of the Tanzanian national healthcare system by examining the relationship of community workforce development and educational development within the nursing school. A series of goals and a work plan are described over a three year period. The project identified structural weaknesses, provided a link between workforce and educational development, and implemented a technology-based delivery system.

\section{INTRODUCTION}

This qualitative case study describes the collaboration between a nursing school in a private University in Tanzania and the faculty of a public institution in Carson, California. The project was proposed initially because the nursing school was unprofitable and the owners believed that the principal investigator could help because of his long history in Tanzania and with the Hubert Kairuki Memorial University (HKMU), and his position as a faculty member at California State University, Dominguez Hills (CSUDH). The study begins by situating the nursing school within the healthcare system of Tanzania. It describes a historical shortage of nurses within the country and the problems and issues faced by HKMU as they attempt to ameliorate the shortage.

This study uses national healthcare goals as a framework and then discusses the relationship of workforce development in the community and educational development within the school of nursing. The case describes a series of goals, objectives and a work plan that guided the design team over a period of three years. Initial activities connected the nursing school in Tanzania with the local community and institutions outside the community. The implementation of an entry-level nursing program, and information and communication technology relating to curriculum development and pedagogy, positioned HKMU to move forward. The study ends with the presentation of a series of recommendations for moving forward. Data, collected primarily through archived documents developed during the project, are presented. 


\section{THE CASE}

In response to the high rate of maternal and child mortality and morbidity in Tanzania, and the shortage of appropriate nursing personnel to address this problem, the principal investigator proposed an initiative to improve Tanzania's nursing program curriculum and infrastructure to more closely align with the needs of the national healthcare system, thus increasing capacity and expanding access to healthcare services in rural and urban environments. The initiative focused on capacity building through Tanzania's three-tiered nursing education curriculum, nursing workforce development, and the use of modern education and information and communication technology (ICT). At its heart is an online learning management system called Moodle that allows front-line health-care workers to expand the reach of scarce nursing resources beyond the urban environment. This approach to the problem views healthcare as a large complex adaptive system. This system involves an educational subsystem and a healthcare subsystem which needed to be linked more efficiently for the entire system to function effectively. Largescale change can be introduced in these systems by introducing and leveraging change at the micro-level, because that is where relationships, interaction, small experiments, and simple rules shape emerging patterns of behavior (see Table 1).

Thus, the development effort was begun at a medical center in Dar es Salaam, Tanzania that included both a clinical and educational arms. It was believed that greater success could be had by developing results at the local level and expanding outward, than by imposing structure from the top down. Once change is established at the local level, the system model can be adapted throughout Tanzania and other African countries. The design team represents collaboration between HKMU, CSUDH, HealthSpan International (HSI), as well as several other contributors. This team included people from different disciplines who brought their collective skills to bear on bringing different parts of the system together.

The project context is that it was a three-year, action research project, called Project Afya. This started in 1997 when the principal investigator first visited a new and growing health care facility in Tanzania, called Mission Mikocheni Hospital (MMH). The private Hubert Kairuki Memorial University (HKMU) began in 1997 after Hubert Kairuki, the founder of MMH, found he could not sustain growth without a reliable stream of trained nurses. The concept of a university that would train high-quality nurses and doctors was born out of a series of meetings and lectures with senior staff, and included the principal investigator as part of his doctoral education. HKMU is fully accredited by Tanzania's Higher Education Council and is now the largest private University in Tanzania.

In 2001, California State University Dominguez Hills (CSUDH) entered into a cooperative agreement with HKMU, which was formalized in 2009 with a memorandum of understanding. The stated goals were to help strengthen the capacity of HKMU to provide high-quality nursing training, conduct high-quality public health research, and to produce highly qualified nurses and public health graduates in increasing numbers. Mobilizing a team of curriculum, faculty development, healthcare, and IT specialists, as well as experienced nursing educators from both universities, project personnel worked both onsite and remotely to develop nursing education that would meet the needs of the national healthcare system.

The project followed the social entrepreneurship model developed by the principal investigator and previously implemented successfully in Tanzania, Ethiopia and Cameroon. The model, called the client consultant system infrastructure (CCSI) is based on the premise that those living in a country are the primary stakeholders in development efforts, have keen insights into what they need to accomplish, and must be an integral part of planning and implementation efforts. Taderera, Hendricks, and Pillay detail a similar approach developed for Zimbabwe (Taderera, Hendricks, and Pillay, 2017). Andrew Scarffe discusses the need for a close understanding of local drivers and barriers in developing international partnerships in health systems (Scarffe, 2017). 


\section{STRATEGIC RESULTS FRAMEWORK FOR TANZANIA}

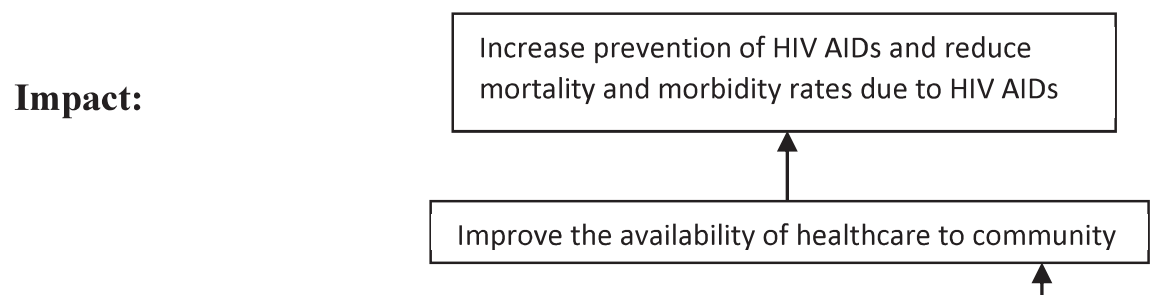

Focal Areas:

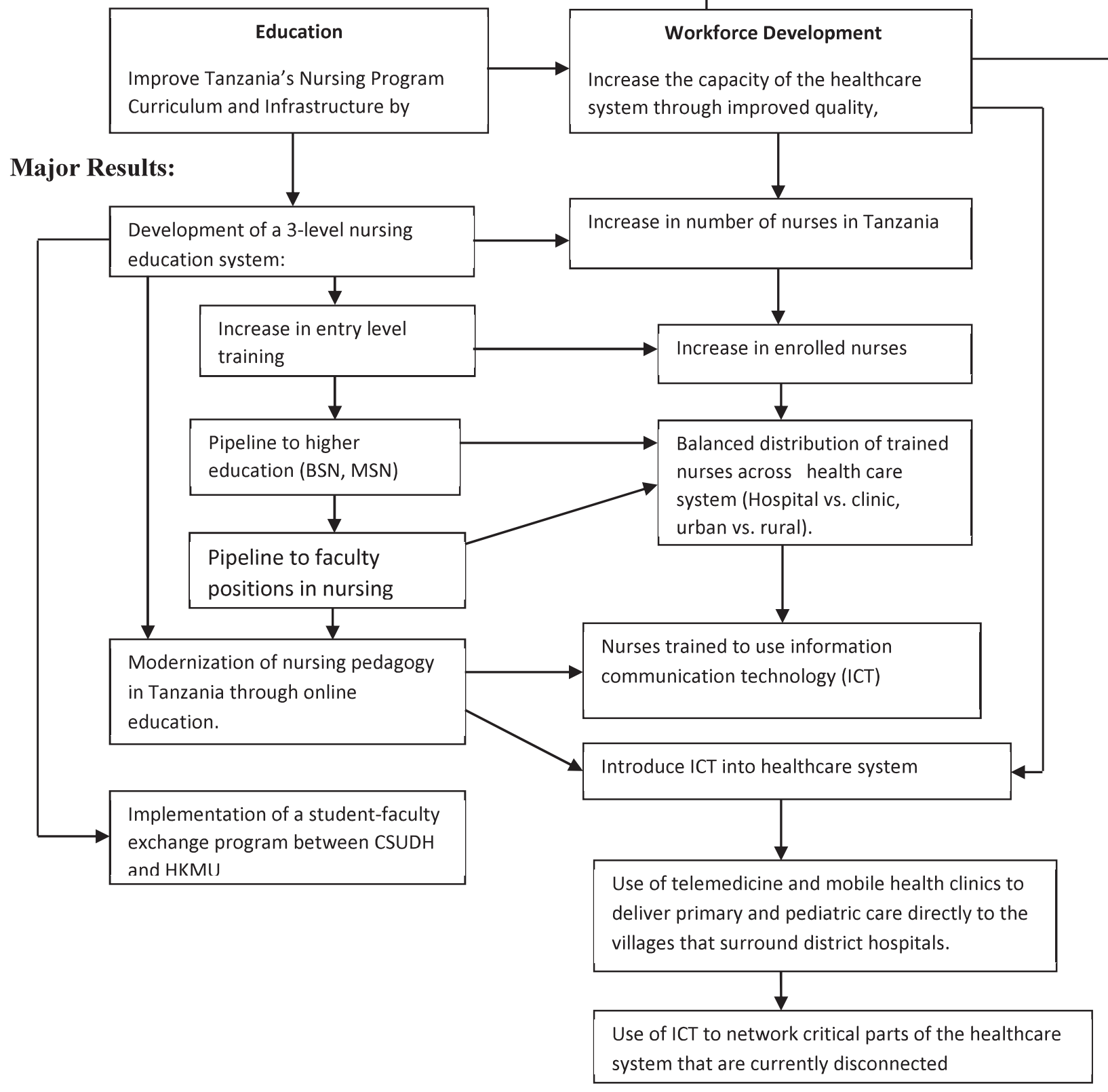

28 Journal of Business Diversity Vol. 18(3) 2018

Introduction of new preventive health techniques that address system requirements, e.g., a Cervical Cancer Screening Program 
In the CCSI, the project director facilitates the input of both partners and works with them to develop the structure around which the project will be built. The CCSI is a mini-organization composed of agents from each of the groups involved in the development effort, including faculty and students from the participating universities, representatives of the National Health System, and the nursing practitioner community.

Members of the CCSI collaborate closely as equals, sharing their resources and expertise and together pursuing effective strategies to achieve project objectives. CCSI membership typically changes as the needs of a project change. Because CCSI members have contributed to the project and are deeply invested in its success, they are able to "sell" concepts to their colleagues far more easily than outsiders attempting to impose solutions. The model is highly cost-effective and particularly lends itself to a sustained effort because once the relationships are established, over time, personnel in the host country or organization become instrumental in carrying out many of the key tasks and activities, while the U.S. partner's role becomes primarily supportive (Katzenstein, 2000; Katzenstein, \& Chrispin 2011).

For this project, CSUDH applied the model within the framework of needs assessment. Emphasizing interactions that bridge cultural barriers, it resulted in mutually agreed-upon goals and objectives. Project personnel from the two institutions jointly developed a strategic implementation plan to address course design, pedagogy design, faculty recruitment, technology, and community relationship-building. They also worked to ensure that the program has measurable outcomes that will be integrated and compatible with Tanzania's overall healthcare system.

\section{THE PROBLEM}

The primary barriers to effective health care in Tanzania are insufficient access to primary care, and an acute shortage of health workers (McKinsey and Company, 2009). Tanzania has a population of more than 43 million and is the fifth poorest country in the world. According to the World Health Organization, the sub-Saharan region in which Tanzania is located has the lowest availability of qualified medical resources and the highest disease burden. The severe shortage of health care workers is considered a main factor in Tanzania's high infant and maternal mortality rates, high infectious disease rates, and low life expectancy. Improving the healthcare of $50 \%$ of the population will contribute to a better functioning society (Uys, \& Klopper, 2013).

The shortage of health-care workers in Tanzania exists at all levels and is exacerbated by the uneven distribution of nursing personnel between rural and urban areas, as well as by systemic issues with Tanzania's nursing programs. There are not enough faculty to support the demand for nursing personnel and low pay and heavy workloads create significant barriers. Clinical supervision is also in short supply as well as classroom capacity, dormitory capacity, and a process to accurately verify enrollment qualifications (I-Tech International Training and Education Center for Health, 2010).

In 2010, the governments of Tanzania and the United States published a five-year partnership framework in support of Tanzania's national response to HIV and AIDS [8]. The framework (see Table 2), the President's Emergency Plan for AIDS Relief (PEPFAR), presented six partnership framework goals as follows:

1. Service maintenance and scale up: to reduce morbidity and mortality due to HIV and AIDS and improve the quality of life for people affected by HIV and AIDS.

2. Prevention: to reduce the number of new HIV infections in Tanzania.

3. Leadership, management, accountability and governance: to provide coordinated, effective, accountable, and sustainable leadership and management for the HIV and AIDS response.

4. Sustainable and secure drug and commodity supply: to strengthen procurement and supply management systems of HIV and AIDS related commodities.

5. Human resources: to ensures human resources capacity necessary for the achievement of quality health and social welfare services at all levels.

6. Strategic and evidence-based decision: to provide timely use of relevant and comprehensive evidence and HIV related planning and decision-making. 


\section{TABLE 2}

\section{PEPFAR GOALS FOR AFRICA}

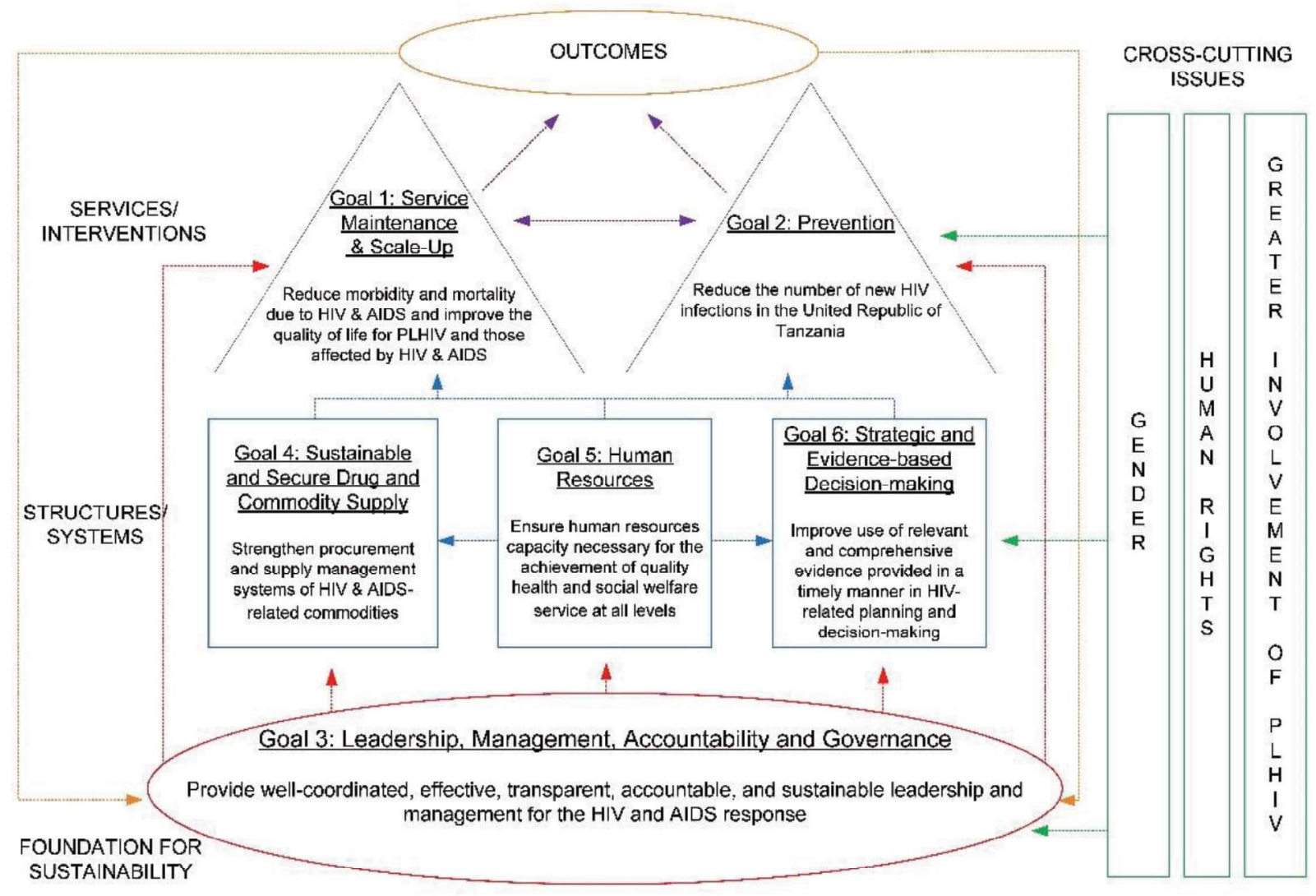

Accomplishment of these goals is impossible without significant increases of health professionals trained to address the issues. From 1993 to 2005 a hiring freeze led to a sharp decline in human resources for health in Tanzania. During this period 23,474 health workers graduated from training institutions, but only $16 \%$ were employed. Budget fluctuations affected the allocation of resources even though expenditures for health care increased from $4 \%$ of the national budget in 1993 to $10.6 \%$ in 2007 (U.S. State Department, 2010).

The health sector is facing a serious human resource crisis that is negatively affecting the ability of the sector to deliver quality health services. In 2006 there was a shortage of 53,000 health professionals, which represented $65 \%$ of the 82,277 needed. Almost $40 \%$ of the total shortage is in the dispensaries, which represent the bulk of health facilities in Tanzania and are responsible for providing primary health care and information at the Ward and Village level. The Minister of Health has increased recruitment of health workers since 2005. As the pool of unemployed health workers is reduced, and needs increase, the shortage gets worse. To address the shortage of healthcare workers, the government has attempted to expand the number of students being trained in health sciences, such a nursing and public health, and to reduce training time. The training system has been unable to keep up. There is not enough faculty or educational infrastructure to handle a significant influx of students. In the meantime, the system loses about 300 human resources in health (HRH) per year through attrition and brain drain to Western countries (United Republic of Tanzania Ministry of Health and Social Welfare, 2008).

There are other issues that complicate the attempts to increase HRH in Tanzania. Salaries of healthcare workers are low, while the cost to educate those workers is not. Education of higher-level 
health workers in the private sector becomes difficult to justify if students have to pay for his/her education. The reward system is not adequate to justify the long payback time and the hard work.

\section{GOALS AND OBJECTIVES}

The overarching goals of this initiative were to address health care deficiencies in Tanzania by:

1. increasing prevention of HIV AIDs and to reduce mortality and morbidity rates due to HIV AIDs.

2. improving the availability of healthcare to the community.

3. improving Nursing Program quality through alignment with national healthcare needs.

4. increasing healthcare system capacity through improved quality, performance and distribution of nurses.

Working in Africa is very different from working in the U.S., and these different worlds provide unique perspectives about development, health and wellness, healthcare capacity and the role of technology. Systems that work in the West do not necessarily work equally well in Africa; and are not necessarily accepted by the client users of the system. In healthcare as in other areas, there is considerable evidence to suggest that the introduction of new technologies invariably creates turbulence within an organization, primarily because the new organizational structures associated with the innovation are not assimilated within the existing status quo.

Turbulence is overcome by the development of structural congruence which develops over time through current interaction among collaborators from different cultures. As structural congruence develops and organizational turbulence subsides, organizations from different cultures and experiences can begin to work together (Katzenstein, \& Chrispin, 2011; Coombs, 1996; Maturana, \& Varela, 1998). Project Afya, was designed from the beginning to address national issues, such as nursing strategies, at the local level. In that way it contributed to the overarching national goals while at the same time improving the situation in the areas that surrounded Mission Mikocheni Hospital and HKMU. HKMU was not connected to the local community, did not have entry-level training for nurses, did not utilize ICT, and did not have a way for Hospitals to access their nurses. This type of dysfunction can be found in nursing education in many African nations (Adetola, Adedeji, \& Popoola, 2017).

Project Afya facilitated structural congruence with learning management system technology, such as Moodle and Blackboard. The strategies and objectives are as follows:

1. To develop a 3-tier nursing education system at HKMU, which is embedded in the local community, that will:

a. provide a pipeline of enrolled nurses into the community.

b. provide a pipeline of enrolled nurses into higher education, i.e., Bachelor of Science in Nursing (BSN) and Master of Science in Nursing (MSN).

c. provide a pipeline of BSNs and MSNs into nursing faculty positions.

2. To modernize nursing pedagogy in Tanzania through online education, thus preparing African nursing graduates to use ICT.

3. To increase the number of nurses in Tanzania.

4. To develop and implement a student-faculty exchange program between CSUDH and HKMU.

5. To build access to service delivery using telemedicine and mobile health clinics to deliver primary and pediatric care directly to the villages that surround district hospitals.

6. To build capacity in service delivery by networking critical parts of the healthcare system that are currently disconnected via ICT.

\section{WORK PLAN}

An environmental scan of the internal and external environment, of the HKMU nursing school, examined strengths, weaknesses, opportunities and threats (see Tables 3 and 4). Dispensaries and health 
centers provide the basis for most healthcare delivered in rural areas in Tanzania. These facilities are typically staffed by enrolled nurses, who also provide a pipeline from the community into nursing schools throughout the country. The design team discovered that the nursing school in effect was isolated from the community and the world at large. Without an entry-level nursing program, the school had no access to entry-level candidates from the local community. Recruiting candidates for their $\mathrm{RN}$ and $\mathrm{BScN}$ programs was difficult because of the competition from other schools whose entry-level nursing program gave them a leg up. Also, without access to a Master's program, HKMU could not provide highly educated nurses to the top of the healthcare system.

TABLE 3

\section{EXTERNAL ENVIRONMENT}

\begin{tabular}{|c|c|c|}
\hline & Opportunities & Threats \\
\hline Economic & $\begin{array}{l}\text { - Huge demand for nursing } \\
\text { personnel, particularly at lower } \\
\text { levels } \\
\text { - Technology infrastructure } \\
\text { improving }\end{array}$ & $\begin{array}{l}\text { - Serious HR crisis in healthcare sector } \\
\text { - Shortage of trained healthcare workers at } \\
\text { all levels } \\
\text { - Loss of HR for health through attrition } \\
\text { and brain drain to Western countries } \\
\text { - Poor salaries; high cost of education } \\
\text { - Inadequate IT infrastructure }\end{array}$ \\
\hline Legal-Political & $\begin{array}{l}\text { - National goals for improving } \\
\text { healthcare } \\
\text { Partnership goals under PEPFAR } \\
\text { for addressing the HIV AIDS } \\
\text { crisis }\end{array}$ & $\begin{array}{l}\text { - Most funding earmarked for large public } \\
\text { institutions }\end{array}$ \\
\hline Socio-cultural & $\begin{array}{l}\text { New learning approaches to } \\
\text { competency-based instruction, } \\
\text { online education, and student- } \\
\text { centered learning hold promise } \\
\text { for greatly expanding education } \\
\text { beyond time and place }\end{array}$ & $\begin{array}{l}\text { - Cultural divide between Western and } \\
\text { African ways of doing things }\end{array}$ \\
\hline International & $\begin{array}{l}\text { Twinning relationship with } \\
\text { CSUDH and HSI brings key areas } \\
\text { of expertise for modernizing } \\
\text { pedagogy and curriculum } \\
\text { development, arranging } \\
\text { - Student and faculty exchanges }\end{array}$ & - High cost of international exchanges \\
\hline
\end{tabular}


TABLE 4

INTERNAL ENVIRONMENT

\begin{tabular}{|c|c|c|}
\hline & Strengths & Weaknesses \\
\hline Mgt \& Org & $\begin{array}{ll}\text { - } & \text { Leadership focused on } \\
\text { continuous improvement. } \\
\text { - } & \text { Strengthening leadership of } \\
\text { nursing program }\end{array}$ & $\begin{array}{l}\text { - Student/faculty/facilities in bacc \& pre-bacc programs } \\
\text { intermingled }\end{array}$ \\
\hline Marketing & $\begin{array}{l}\text { HKMU brand respected in } \\
\text { Tanzania }\end{array}$ & $\begin{array}{l}\text { - No programs to promote brand in nursing education } \\
\text { - No program to target potential students }\end{array}$ \\
\hline $\begin{array}{l}\text { Human } \\
\text { Resources }\end{array}$ & $\begin{array}{l}\text { Qualified faculty of School } \\
\text { of Nursing }\end{array}$ & $\begin{array}{l}\text { - Lack of job analysis \& job evaluation } \\
\text { - Lack of training/development opportunities \& IT } \\
\text { - Internal resistance to change } \\
\end{array}$ \\
\hline Finance & $\begin{array}{l}\text { - } \begin{array}{l}\text { Medical programs generate } \\
\text { sufficient income to sustain } \\
\text { nursing programs }\end{array} \\
\end{array}$ & $\begin{array}{l}\text { - Nursing programs aren't self-sustaining (unprofitable } \\
\text { business model) }\end{array}$ \\
\hline Info Tech & $\begin{array}{l}\text { - Access to computer lab, } \\
\text { video projectors } \\
\text { - Availability of IT specialist } \\
\text { \& Moodle }\end{array}$ & - Unreliable internet \& electricity \\
\hline $\begin{array}{l}\text { Students \& } \\
\text { Graduates }\end{array}$ & $\begin{array}{l}\text { - Students highly satisfied } \\
\text { with program }\end{array}$ & $\begin{array}{l}\text { - Small number of students \& graduates } \\
\text { - No pipeline of students into nursing programs at } \\
\text { HKMU }\end{array}$ \\
\hline Curriculum & $\begin{array}{l}\text { - Accredited programs for } \\
\text { diploma, RN, BSN }\end{array}$ & 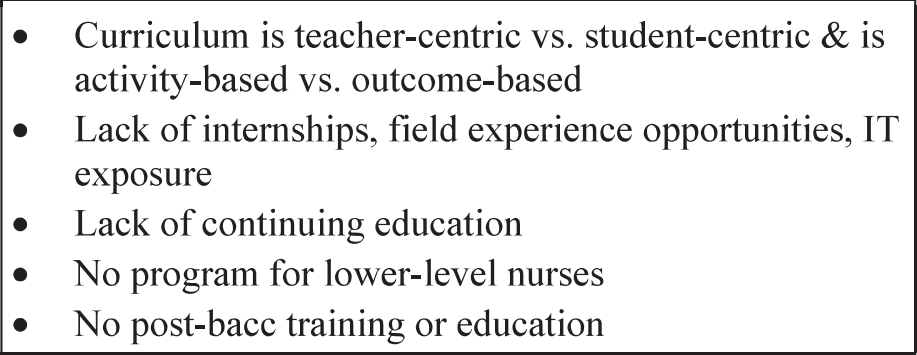 \\
\hline Facilities & $\begin{array}{l}\text { Sufficient classrooms, } \\
\text { offices, labs, dormitories, } \\
\text { cafeteria for current } \\
\text { programs }\end{array}$ & $\begin{array}{l}\text { Lack of room for growth due to competition for space } \\
\text { with medical programs and hospital }\end{array}$ \\
\hline
\end{tabular}

There is also a serious financial issue. To attract candidates, the nursing school had to price their RN and $\mathrm{BScN}$ programs low. If they priced the programs to be self-sustaining, there won't be enough students to cover costs. If prices are raised to make a profit, students will not be able to pay for their education in a short enough time period to make their investment worthwhile. A nurse earning $\$ 180$ per month would have to work approximately 15 years to pay for her education. There is also a shortage of financing options that exacerbates the problem. HKMU offers medical degrees as well as nursing degrees and uses income from their medical students to fund nursing programs.

The design team found the curriculum to be a major impediment to streamlining the nursing program and gaining the necessary efficiency to make the program self-sustaining. The curriculum was teacher- 
centered and activity-based rather than student-centered and outcome-based. The opportunity for field experience at $\mathrm{MMH}$ and government clinics was limited. There was minimal communication between the hospital and the nursing school.

\section{ACCOMPLISHMENTS}

The faculty and staff of both institutions organized and developed an effective CCSI that consisted of Management and African specialists from CSUDH, and nursing and technology specialists from both institutions. The development team connected the HKMU nursing program with the local community, creating opportunities for people to obtain entry-level nursing credentials while providing the local community with entry level nurses. Development of a three-tiered nursing program began with the implementation of an enrolled nursing curriculum which offered primary nursing education for entry level nurses. Students were recruited from the local community. HKMUs objective is to graduate 100 enrolled nurses annually from HKMUs School of Enrolled Nursing. Ultimately, the best of these students will be available for higher education, such as HKMUs, BSN program and CSUDH's MSN program. The initial enrollment was 60 students.

The development team facilitated access to CSUDH's on-line MSN program in which nurses with BSN credentials could earn a Master's degree. That connection remains open but as of this writing has not been completed. The development team also introduced education technology and learning management systems to extend the reach of HKMU, allowing them to reach practicing nurses in the community to provide continuing education. The ultimate goal of the ICT component of this project is to continually upgrade nursing curriculum, via access to the latest in nursing education and information, and to transfer that to rural healthcare workers. The development team provided hardware, software, systems and training to faculty and technical staff at HKMU, giving them the capacity to do this.

The CCSI also expanded the reach of HKMUs healthcare capacity through the implementation of maternal and child health clinics in communities surrounding the university. These clinics provide prenatal and postnatal care, well baby visits, vaccinations, vitamins, HIV testing, and cervical cancer screening. The clinics meet weekly and are staffed by MMH nurses. In addition to delivering quality healthcare, the clinics enhanced the relationships between nurses and the local community, thereby inserting modern healthcare deep into the community. HKMU has developed the technical capacity to connect with universities worldwide. Faculty from CSUDH's nursing school have traveled to Tanzania to work with HKMU's nursing faculty to develop online teaching and learning management skills.

\section{CONCLUSIONS}

Relationship building between institutions and individuals is crucial to the success of a collaborative project. The use of the CCSI as a go-between facilitates transfer of information and skills, bridges cultural barriers, and allows creative solutions to emerge. Addressing national issues at the local level allows participants to focus on results rather than process. Implementing PEPFAR national goals for reduction of HIV-AIDS is a daunting task, however, projects such as Project Afya allows HIV testing for mothers and children. It also allows the development of human resources for health at the local level, contributing to the accomplishment of national priorities.

The introduction of technology into the healthcare system of developing African countries is crucial to the completion of PEPFAR goals. Technology-mediated healthcare practice and education connects universities and hospitals, such as HKMU and MMH, with the world body of knowledge. Healthcare professionals who graduate from universities such as HKMU with technology skills will be able to remain current in the field, raising the overall level of healthcare in Africa. 


\section{FURTHER STUDY}

At the conclusion of the study the design team met with the board of directors of HKMU and MMH and made the following recommendations:

1. To revise and enhance nursing curriculum to ensure that it is consistent with world standards, and to prioritize national goals now that the technological capability to access worldwide knowledge bases and systems is in place.

2. To create a program for faculty development, including support for research, conferences and continuing education, to enhance the institution and its students.

3. To expand learning technology, integrating learning management systems into ground-based courses, thereby increasing the efficiency of nursing faculty.

4. To create an enterprise-wide information and communication technology system and to expand international collaboration. This would include access to CSUDH's on-line MSN and would raise the quality and reputation of HKMU. Now that the institution has the technical capacity, it should use that capacity to reach out to practicing nurses to offer continuing education in the field. Online and hybrid courses can overcome the substandard physical infrastructure and lack of time to attend ground-based classes.

Looking back on this project, HKMU has been helped to advance their ability to serve the people of Tanzania. These efforts have led to the foundation on which the HKMU School of Nursing can grow. The experience of the principle investigator over the past 20 years with the staff of this institution is that once they see the way forward they will adapt what they have learned to fit the needs of their institution and the people of Tanzania. They will take what the design team has done and twist and bend it until it becomes Tanzanian, which is how it should be.

The following is from the HKMU School of nursing's current catalog:

"Mikocheni School of Nursing has been appointed by the Ministry of Health Social Community Development, Gender, Children and Elderly in collaboration with AMREF (AMREF Health Africa), to be among the few Nursing Schools in the country that will run the Diploma in Nursing program, through the e-learning model.

This method combines electronic learning using computers and face to face sessions. The e-learning approach allows nurses to remain at their workplace for most of the study time and enables them to study at their own pace, with minimal disruption to their work schedules, taking into consideration the practical oriented nature of nursing and midwifery education" (HKMU, 2017).

\section{RECOMMENDATIONS FOR INTERNATIONAL PROJECTS IN AFRICA}

International development projects in Africa should be strongly connected to the community. Sustainable change can be accomplished by introducing change at the lowest possible level. The lowest levels are where relationships, normal human interaction, and simple improvements can affect the success or failure of larger-scale change. Other researchers, including Andrew Scarffe agree that it is the local African drivers and barriers that are most instrumental in effective international partnerships (Scarffe, 2017).

The client consultant system infrastructure (CCSI), described in this case study, is based on acknowledging African partners as the primary and stakeholders in development efforts. They, much more than foreign partners, have the relevant insights into how and what should be accomplished. Relationships must be equal and very long-term, as members are in a CCSI. Because African CCSI members have contributed to the project from the beginning, they are invested in its sustainability. This approach works better than solutions that are imposed from outside. The CCSI model is cost-efficient and is more likely to result in permanent change, because over time, host country members end up performing all the major activities, while the U.S. partner becomes supportive (Katzenstein, 2000; Katzenstein, \& Chrispin, 2011). 


\section{REFERENCES}

Adetola OB, Adedeji IA, Popoola O. (2017). Systems Theory Analysis of Ebola Virus Disease and Nursing Needs in the West African Sub-Region. International Journal of Healthcare

Management, December 2017, Retrieved from https://doi.org/10.1080/20479700.2017.1418278.

Coombs RA. (1996). The Politics of IT in Organizations. In W. Dutton's, Information and

Communication Technologies: Visions and Realities. London: Oxford Press.

HKMU (2017). HKMU School of Nursing Catalog. Retrieved from www.hkmu.ac.tz/nursing/school.

I-Tech International Training and Education Center for Health. (2010) Scaling Up Human Resources for Health: A Situational Analysis of Government Nursing Schools in Tanzania.

Katzenstein J. (2000). Developing and Innovative International Consulting Model with a Private Healthcare System in Tanzania. UMI dissertation services.

Katzenstein J, Chrispin B. (2011). Social Entrepreneurship, and the New Model for International Development in the 21st Century. Journal of Developmental Entrepreneurship, March 2011.

Maturana HR, Varela FJ. (1998). The Tree of Knowledge: the biological roots of human understanding. Shambhala, Boston \& London

McKinsey and Company. (2009). A Practical Approach to Health System Strengthening in Sub Saharan Africa. Health International 2009, Volume 9. Retrieved from https://www.mckinsey.com/.../mckinsey/...service/Healthcare\%20Systems\%20and\%20.

Scarffe AD. (2017). International Agreements for Health Systems Development: Nature, Drivers, Barriers, and Benefits of International Partnerships. International Journal of Healthcare Management, November 2017, Retrieved from https://doi.org/10.1080/20479700.2017.1397306.

Taderera BH, Hendricks SJH, Pillay Y. (2017). Human Resource for Health Policy Interventions Towards Health Sector Reform in a Zimbabwean Peri-Urban Community: A Decision Space Approach. International Journal of Healthcare Management, November 2017, Retrieved from https://doi.org/10.1080/20479700.2017.1407523.

United Republic of Tanzania Ministry of Health and Social Welfare. (2008). Human Resources for Health Strategic Plan 2008-2013.

U.S. State Department. (2010). Five-Year Partnership Framework in Support of the Tanzanian National Response to HIV and AIDS, 2009-2013. Agreement between US Government and Tanzania Government.

Uys LR, Klopper HC. (2013). The State of Nursing and Nursing Education in Africa: A Country-byCountry Review. Indianapolis, IN: Sigma Theta Tau International. 